\title{
Contributions of Ultrastructural Studies to the Cell Biology of Trypanos- matids: Targets for Anti-Parasitic Drugs
}

\author{
Camila Marques Adade and Thaïs Souto-Padrón*
}

Departamento de Microbiologia Geral, Instituto de Microbiologia Paulo de Góes, Universidade Federal do Rio de Janeiro, Av. Carlos Chagas Filho 373, Ilha do Fundão, 21941-902, Rio de Janeiro, RJ, Brazil

\begin{abstract}
Protozoan parasites cause disease in humans worldwide, and many fall into the genera Trypanosoma and Leishmania; these parasites are responsible for African trypanosomiasis, Chagas disease and the different forms of Leishmaniasis. Strategies for the development of new drugs against these protozoans have been based on their cell biology and biochemistry complemented by the use of electron microscopy. Trypanosoma and Leishmania have special organelles that are involved in metabolic pathways, which are very distinct from those in mammalian cells; these organelles are potential drug targets. Scanning and transmission electron microscopy can identify not only the target organelles but also alterations to the cell surface and ultrastructural changes that characterize distinct forms of programmed cell death.
\end{abstract}

Keywords: Trypanosoma cruzi, Leishmania, African trypanosomes, Chemotherapy, Ultrastructure.

\section{INTRODUCTION}

Parasitic protozoans of the genera Trypanosoma and Leishmania infect millions of people around the world. The diseases (African sleeping sickness, Chagas disease and leishmaniasis) caused by these parasites are in the group of 13 neglected tropical diseases classified by the World Health Organization. All of them occur in areas of extreme poverty and are forgotten by the government, while chemotherapy in patients is not economically attractive to pharmaceutical companies. Other factors that make this situation even worse are the lack of effective vaccines, the use of old, toxic drugs with variable efficacy and parasite resistance, the parenteral administration and the length of treatment [1-3].

Despite the lack of interest of different governments in eradicating these diseases, the trypanosomatids (even those not pathogenic to mammals) are the primary focus of various research groups around the world as important models for studying certain aspects of basic eukaryotic cell biology. Ultrastructural, physiological, biochemical and molecular approaches have shown that trypanosomatids (like other protozoan parasites) present special organelles, different metabolic pathways and special classes of enzymes. These features can be targeted for the development of new specific chemotherapeutic agents, including those isolated from natural compounds that can minimize the toxic effects on the host [3, 4-7].

In this review we will discuss how electron microscopy can help to identify the cellular locations of molecular targets of several drugs in different developmental stages of Trypanosoma brucei, T. cruzi and Leishmania spp. We will

\footnotetext{
*Address correspondence to this author at the Laboratório de Ultraestrutura e Biologia Celular, Instituto de Microbiologia Paulo de Góes, Universidade Federal do Rio de Janeiro, CCS, Bloco I, Av. Carlos Chagas Filho 373, Ilha do Fundão, 21941-902, Rio de Janeiro, RJ, Brazil; Tel: 55-21-2562-6738; Fax: 55-21-2560-8344; E-mail: souto.padron@micro.ufrj.br
}

also describe in detail the effects of drugs on the ultrastructure of the parasites.

\section{ULTRASTRUCTURAL ASPECTS OF DRUG- TREATED PARASITES}

Scanning and transmission electron microscopy have been frequently used in the study of drug-treated parasites. With the scanning electron microscope (SEM), changes in cell shape (shrinking, swelling, twisting), loss of the flagellum and cell membrane rupture can be observed. With the transmission electron microscope (TEM), the fine structure of the cell membranes and the different organelles can be observed (Fig. 1). Changes in composition of the organelles can be analyzed by cytochemical techniques, X-ray microanalysis or electron spectroscopy with loss of energy [8]. A brief explanation of the normal morphology of the parasites and the mechanism of action of the different classes of drugs will be presented.

\subsection{Mitochondria}

Trypanosomatids have only one highly ramified mitochondrion distributed throughout the protozoan body as revealed by observations of thick serial sections and of whole cells with high-voltage electron microscopy [8]. The mitochondrion is present in all developmental forms of the different trypanosmatids, and significant changes in the morphology of the organelle were observed in African Trypanosomes and in Herpetomonas samuelpessoai depending on the metabolic activity of the parasites. The morphological differences observed included changes in the relative volume of the mitochondrion in relation to the whole cell, the presence of cristae and the expression of mitochondrial enzymes. Although no differences in mitochondrial structure were observed among the developmental stages of $T$. cruzi and Leishmania, differences in molecular composition cannot be ruled out and could be important to define new molecular targets. 
The most frequent effect of different chemotherapeutic agents on trypanosomatid mitochondria is swelling of the organelle, the intensity of which varies according to the type and concentration of the drug and the time of incubation [9, $10]$.

Cationic drugs, such as crystal violet, which are used to prevent transfusion-associated Chagas disease and aromatic diamidines were the first drugs to be used in chemotherapy against pathogenic trypanosomatids [11-15]. The effect of crystal violet on $T$. cruzi is due to enhancement of production of reactive oxygen species (ROS) that inhibit mitochondrial respiration and cause its swelling, which is more intense in trypomastigotes [14].

Aromatic diamidines (such as pentamidine) have been used with success for more than 60 years in the therapy and prophylaxis of African trypanosomiasis and antimonyresistant visceral leishmaniasis [16, 17]. They have been described as DNA binders but also inhibit multiple classes of enzymes such as proteases, topoisomerases, polymerases, and others [15]. More recently, new diamidine-related analogues were developed that present improved anti-parasitic activity against $T$. cruzi and Leishmania $[18,19]$. In T. cruzi, some of the new compounds (classified as reversed amidines) presented a high level of activity against amastigotes and trypomastigotes both in vivo and in vitro [18-26]. Ultrastructural analysis showed that the different aromatic diamines displayed similar effects in T. brucei, T cruzi and Leishmania, characterized by the presence of swollen mitochondria presenting low electron-density structures, fragmentation of the membrane and crista and mitochondrial disruption [12, 13, 18, 20, 23, 24, 27-32].

T. cruzi and Leishmania mitochondria are altered when the parasites are incubated in the presence of sterol biosynthesis inhibitors (SBIs). Sterols are constituents of cellular membranes that are essential for their normal structure and function. The success of SBIs in the treatment of Chagas disease and leishmaniasis is mainly due to a particular aspect of sterol biosynthesis in these parasites: unlike mammalian cells and similar to fungi, some members of the Trypanosomatidae family synthesize a special class of sterols (i.e., ergosterol and other 24-methyl sterols) instead of cholesterol. Ergosterol biosynthesis depends on the presence of a specific enzyme, $\Delta^{24(25)}$ sterol methyltransferase (SMT), which is not found in mammalian cells, and the use of its specific inhibitors has potential as an effective chemotherapy [9]. Several drugs that interfere with sterol biosynthesis were used in studies with T. cruzi, T. brucei and Leishmania. These include statins, which act on the mevalonate pathway by inhibiting $\mathrm{HMG}-\mathrm{CoA}$ reductase [33]; biphosphonates, which interfere with the isoprenoid pathway in the step catalyzed by farnesyl diphosphate synthase (FDS) [34]; zaragozic acid and quinuclidines, which are inhibitors of squalene synthase (SQS) [35]; allylamides such as terbinafine, which are inhibitors of squalene epoxidase [33]; azoles such as ketoconazole, fluconazole, itraconazole, voriconazol and pozoconazole, which inhibit C14 $\alpha$-demetilase; and azasterols, which inhibit SMT (Figs. 2A, C, D, H).

Morphological changes observed in the mitochondria of trypanosomatids can be explained by the presence of ergosterol in their membranes [36]. Ketoconazole produces an intense swelling of the mitochondrion, which may occupy up to $80 \%$ of the cell volume in $T$. cruzi with loss of inner membrane organization and matrix contents [37]. The combination of ketoconazole and terbinafine, in addition to inducing swelling, also caused the formation of paracrystalline arrays within the matrix of the Leishmania mitochondrion $[37,38]$. SQS inhibitors produce mitochondrial swelling, separation of the outer and inner membranes and the presence of myelin-like figures and concentric membranes in the mitochondrial matrix [39-42] (Fig. 2D). The same effects were observed after treatment of $T$. cruzi and Leishmania with SMT inhibitors [43-46] (Fig. 2A). No alterations in mitochondrion structure have been described in $T$. cruzi after incubation in the presence of miconazole or econazole [47].

Lysophospholipid analogues (LPA) are a class of compounds that have been developed as anticancer agents. Their mechanism of action is based on their ability to insert into the membrane lipid bilayer and to change properties such as permeability, fluidity and signal transduction. LPA also interfere with the synthesis, breakdown and modification of membrane lipids [48]. More recently, these compounds were also tested against Leishmania and T. cruzi [49]. Miltefosine, edelfosine and ilmofosine caused swelling of Leishmania mitochondria and the presence of concentric membranes in the mitochondrial matrix [50]. No alterations were observed when $T$. cruzi was treated only with edelfosine; however, combined treatment with LPA analogues plus ketoconazole induced mitochondrial swelling [51, 52].

Lapachol and $\beta$-lapachone are naphtoquinones isolated from Tabebuia spp. trees that show activity against viruses, tumoral lineages and pathogenic microorganisms [53]. The mechanism of action of these compounds involves the generation of free radicals, which promote mitochondrial dysfunction. The effect of naphtoquinones and their naphthoimidazole derivatives on mitochondrion structure are drastic, with an intense swelling and the presence of intramitochondrial vesicles [54-58] (Figs. 2B, E).

The polyamine biosynthetic pathway has been shown to be an effective target for treatment against diseases caused by protozoan parasites. In trypanosomatids, the inhibition of polyamine synthesis impairs the synthesis of trypanotione, which is essential for protection of the parasite against reactive oxygen species produced by the host [59]. Interference in the synthesis of polyamines with eflornithine or DFMO (difluoromethylornithine), a selective irreversible inhibitor of ornithine decarboxylase (ODC), induces changes in the differentiation process in $T$. b. gambiense. However, it was not effective against Leishmania or T. cruzi due to differences in the gene and an inability to produce significant amounts of putrescine, respectively [60-63]. Use of the putrescine analogue 1,4-diamino-2-butanone (DAB) caused inhibition of the proliferation of Leishmania and T. cruzi and severe damage to the mitochondrion characterized by swelling, fenestration and the presence of few cristae [64-68].

Alternative treatments have been introduced into the chemotherapy of parasitic diseases, and many studies based on the use of synthetic compounds, plant extracts, natural products and venoms have been published. The biological activity of natural products is mainly associated with the presence of compounds such as flavonoids, aromatic acids, 


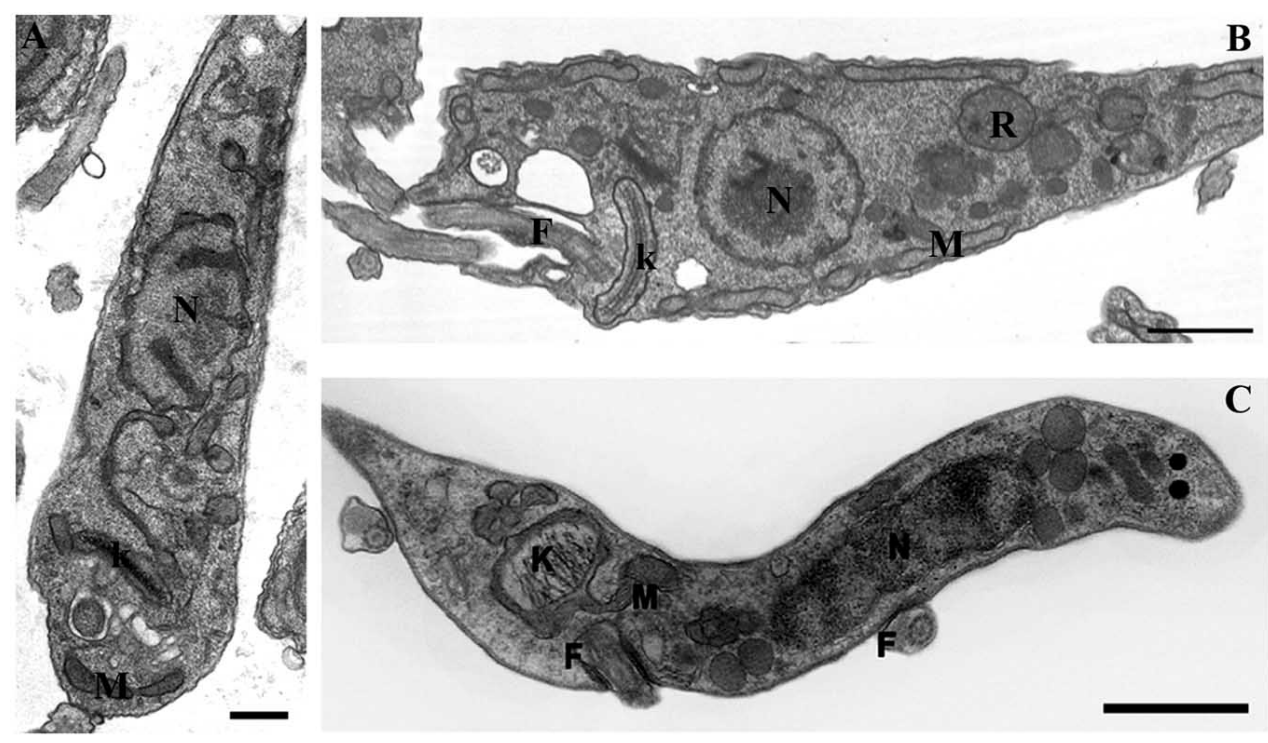

Fig. (1). Ultrathin sections showing untreated parasites presenting typical morphologies. (A) An L. amazonensis promastigote. (B-C) A T. cruzi epimastigote and a trypomastigote, respectively. N, nucleus; K, kinetoplast; M, mitochondrion; F, flagellum; R, reservosome. Bars: 1 $\mu \mathrm{m}$. (A) Courtesy of J. C. Rodrigues. (B) Image from T. Souto-Padrón. (C) Image reproduced with permission from Ref. [58] @) (2009) Elsevier.

peptides and others. Although many studies have been published on T. cruzi, T. brucei and Leishmania, few have characterized the effects of these products on the ultrastructure of the parasites. Mitochondrial swelling and the presence of concentric membrane structures in its matrix were observed after incubation of Leishmania and T. cruzi with any of the following: linalool-rich essential oil of Croton cajucara [69], usnic acid from the lichen Cladonia substellata [70], extract of the marine sponge Plakortis angulospiculatus [71], extract of the seeds of Pterodon pubescens with geranylgeraniol (GG-OH) being the most active fraction [72]), propolis [73], taxol isolated from Taxus brevifolia [74], dinitroaniline herbicides [75], $\beta$-carbolines [76], chalcones from Piper aduncum [77], or neolignan from leaves of Piper regnellii [78].

\subsection{Kinetoplast}

The kinetoplast is a fibrous network of the mitochondrial DNA (kDNA) of the protozoa Trypanosomatidae and Bodonidae. The kDNA, which represents about $30 \%$ of the total cellular DNA, may be dispersed or concentrated in a specialized region of the mitochondrion near the basal body, from which the flagellum emerges [79]. The kinetoplast shape and its localization relative to the nucleus vary according the developmental stage of the different trypanosomatids. Two main forms are observed in $T$. cruzi, T. brucei and Leishmania: a compact rod- or bar-shaped structure observed in epimastigotes, promastigotes and amastigotes and a round form with a more disperse array of the kDNA filaments, which is found in trypomastigote forms. The kDNA is composed of two circular types of DNA, maxicircles (small in number), which encode rRNAs and mitochondrial proteins, and thousands of minicircles, which encode guide RNAs that modify the maxicircle transcripts in a process known as RNA editing. According to Motta, maxicircles and minicircles are connected in a special catenated network array that resembles the chain mail of medieval armor [80]. Kinetoplast DNA minicircles have extensive closely-spaced phased
AT sequences that yield curved double-helical structures and provide potential cellular targets for diamidines that have AT sequence binding specificity [81].

The main alteration observed in the kinetoplast as an effect of the different drugs cited above is the disorganization of the kDNA network. There are different grades of disorganization such as: a) looser organization of the DNA filaments in the kDNA network; b) fragmentation of the kDNA, forming many clusters of electron-dense structures inside the mitochondrion; and c) compaction and multiple kDNAs.

Looser kDNA organization is observed when parasites are incubated with naphtoquinones and naphthoimidazoles [55-58] (Fig. 2E). Sometimes, the disorganization of the kDNA network, which has mainly been observed in trypomastigotes, seems to be the result of the severe swelling of the mitochondrion and the loss of the inner membrane. In contrast, aromatic diamidines [18, 20-23], natural and synthetic $\beta$-carbolines [76], topoisomerase inhibitors [80, 82, 83], and DAB [68] cause a drastic effect: the destruction or fragmentation of the kDNA network in promastigotes and amastigotes of Leishmania and in trypomastigotes of $T$. cruzi. These effects were not observed in the kinetoplasts of epimastigote forms of T. cruzi. It is important to note that the looser kDNA aspect observed in pathogenic trypanosomatids after chemotherapy is not similar to the constitutive looser arrangement observed in endosymbiont-bearing trypanosmatids, such as Blastocrithidia culicis, Crithidia deanei and Bodo spp. [80].

Compaction of the kDNA filaments and the presence of multiple kinetoplasts were obtained after treatment of $T$. cruzi epimastigotes with piperine, which is an alkaloid of the Piper species. In some parasites, more than one individualized kinetoplast can be observed, mimicking the effects of cytoskeleton inhibitors. In other parasites, however, up to three kDNA bars can be seen inside the same mitochondrion [84] (Fig. 2J). 
No structural changes in the kDNA network of $T$. cruzi or Leishmania were described in the presence of LPA analogues or SBIs [37, 39-42, 44-46, 50, 52].

\subsection{Nucleus}

The trypanosomatid nucleus presents a typical nuclear membrane with pores, condensed chromatin of varied density dispersed throughout the nuclear matrix up to the nuclear periphery. The nuclear envelope remains intact during the entire division process, with the appearance of intranuclear microtubules, chromatin dispersion and initiated formation of of dense plates, the number of which varies according to the trypanosomatid species [8].

Some ultrastructural effects observed in the nucleus in the presence of different drugs indicate which death pathway the protozoan is undergoing. Different compounds may induce different types of programmed cell death (PCD), including apoptosis (type I PCD), autophagic cell death (type II PCD) and programmed necrosis (type III PCD) [10, 57, $58]$.

Aromatic diamidines and related analogues are DNA minor groove-binding ligands at AT sequences, and they exhibit strong antiparasitic activity [17]. Furamidine (DB75), its $N$-phenyl-substituted analogue (DB569) [18], and reversed [22, 23] and aromatic diamidines [26, 85] induce severe alterations in nuclear morphology. After DB75 and DB569 treatment, $T$. cruzi trypomastigotes presented characteristics of type I PCD [20, 21].

Treatment of L. chagasi promastigotes with ER-119884, an SQS inhibitor, resulted in altered nuclear chromatin organization with some alterations in the nuclear envelope [42].

One of the most remarkable ultrastructural effects observed in $T$. cruzi treated with naphthofuranquinones is strong nuclear envelope swelling [57, 58]. Similar effects were seen in L. chagasi promastigotes treated with telocinobufagin, a steroid isolated from Rhinella jimi parotoid macrogland secretions [86], and in T. cruzi forms treated with Ocimum basilicum essential oil [87] or L-leucine methyl ester (Leu-OMe) [88], where the condensed nuclear material became separated from the nuclear membrane with leakage of its content.

Treatment with different DNA topoisomerase inhibitors causes morphological alterations to the parasites' nuclei. Characteristics like nuclear envelope distension and chromatin condensation were observed in $T$. cruzi epimastigotes after incubation with bacterial DNA topoisomerase type II [89]. Recently, the use of aspartyl peptidase inhibitors (PIs) has been demonstrated to exert a direct effect on Leishmania [90, 91]. L. amazonensis promastigotes treated with lopinavir, an HIV PI, presented condensed chromatin close to the nuclear envelope, a feature suggestive of apoptotic death [91].

T. cruzi trypomastigotes treated with suramin exhibited an altered nuclear division pattern and frequently presented irregular or multiple nuclei [92]. Vinblastin-resistant L. amazonensis also presented dysfunctional cytokinesis, in which the resistant promastigotes showed multiple nuclei [93]. This characteristic was found in parasites treated with the squalene synthase inhibitors BPQ-OH, ER-119884 and E5700; promastigotes were frequently multinucleate (Fig. 2F) with unusual chromatin condensation [40, 41]. L. amazonensis amastigotes treated with edelfosine also presented abnormal numbers of nuclei [50].

\subsection{The Cell Surface}

The cell surface of trypanosomatids, as observed by TEM, is composed of three different components: the cell coat (or glycocalyx), the cell membrane and the subpellicular microtubule layer. The cell coat is in direct contact with the extracellular medium and is composed of oligosaccharides associated with membrane lipids and proteins. The use of freeze-fracture and freeze-etching with TEM has shown that the cell membrane of trypanosomatids presents domains characterized not only by a distinct chemical composition, but also by association with the sub-pellicular microtubules. The first and largest domain is composed of the membrane lining the cell body. The second and the third are the flagellar membrane and the flagellar pocket membrane, respectively [94].

Different drugs have different effects on the cell body and the flagellar membranes (Figs. 2I). Aromatic diamidines [26] and reversed diamidines [22, 23] cause detachment of the plasma membrane in areas where sub-pellicular microtubules are not observed. The presence of blebs budding from the cell body membrane and from the flagellar membranes are observed in epimastigotes of $T$. cruzi and promastigotes of Leishmania amazonensis after treatment with SMT $[39,46]$ and SQS inhibitors [41], respectively. Rupture of the flagellar membrane was also observed in promastigotes of Leishmania chagasi incubated in the presence of BPQ-OH, an SQS inhibitor [42].

Synthetic naphtoquinones caused the formation of blebs in the plasma and flagellar membranes of $T$. cruzi epimastigotes [58]. Naphthoimidazoles derived from $\beta$-lapachone showed a preferential effect on trypomastigotes in which bleb formation was observed throughout the cell body and flagellar membranes. Blebs associated with the cell body membrane did not present any sub-pellicular microtubules [57].

Lysophospholipid analogues caused the formation of blebs in L. amazonensis and T. cruzi, and the effects were more evident when edelfosine, miltefosine and ilmofosine were combined with ketoconazole [50-52] (Fig. 2F).

Plasma membrane disruption was described after treatment of $T$. cruzi and $T$. bruce $i$ with antimicrobial peptides such as defensins and cathelicidins, respectively [95, 96], and in Leishmania after incubation with cecropin A-melittin peptides and with the essential oil of Croton cajucara [69, 97].

The last kind of cell surface change observed after treatment of trypanosmatids with different drugs is alterations in the amount and/or localization of surface molecules. Docampo et al. showed that treatment of $T$. cruzi with miconazole and econazole caused enhanced response of the parasite to the lectins WGA (wheat germ agglutinin) and PHA (phytohemagglutinin) [47]. Treatment of T. cruzi with suramin, a symmetrical polysulfonated derivative of urea used in the prophylactic treatment of human trypanosomiasis in Africa, caused increased activity of a $\mathrm{Mg}^{2+}$ ecto-ATPase and the 
FRA antigen and redistribution of negative surface charges. Alterations in extracellular components in the region of adhesion between the cell body and the flagellum and an increase in the adhesion of epimastigotes to resident macrophages were also observed [92, 98, 99] (Fig. 2L).

\subsection{Cytoskeleton}

Trypanosomatids present a continuous layer of microtubules immediately below the cell membrane, named the sub-pellicular microtubule layer. They are distributed throughout the protozoan body, with the exception of the flagellar pocket. The number of microtubules varies in different regions of the body of the parasite, but they are regularly spaced and connected by filaments to each other, to the inner face of the plasma membrane and to cytoplasmic organelles, such as the endoplasmic reticulum. One of the characteristics of the sub-pellicular microtubules is their high proportion of acetylated and/or polyglutamylated tubulins, which make them very stable [100]. Although actin and actin-binding proteins have been characterized in trypanosomatids, in $T$. cruzi they do not seem to be associated with sub-pellicular microtubules, as observed in Leishmania [101].

No damage to sub-pellicular microtubules was observed after treatment of T. cruzi and Leishmania with taxol, colchicine, vinblastine, trifuraline and ansamitocin P3, piperine or suramin. However, changes in the shape of the parasites, the presence of multiple flagellae, aberrant cell types with multiple kinetoplasts and absence of a nucleus were observed; these changes are probably due to incomplete differentiation and cytokinesis [74, 75, 84, 92, 102, 103]. Disorganization of the sub-pellicular microtubule layer was only observed in amastigotes of $T$. cruzi incubated in the presence of reversed amidines [22, 23].

\subsection{Endoplasmic Reticulum and Golgi Complex}

The endoplasmic reticulum (ER) and the Golgi complex (GC) in trypanosomatids have the same basic structure as that observed in all eukaryotic cells. The localization of the GC may vary according to the developmental form analyzed, but in all cases the CG remains near the flagellar pocket. Different classes of drugs affect the physiology of the ERGolgi system, resulting in ultrastructural changes.

Sterol biosynthesis inhibitors have pronounced effects on the ER and GC [41]. Treatment with terbinafine and different azole derivatives caused modifications in ER-GC structures, which were characterized by the presence of large multivesicular bodies and autophagic structures [37, 38]. The inhibition of squalene synthase (SQS) by different inhibitors, such as BPQ-OH, ER-119884 and E5700, caused disorganization and fragmentation of Golgi complex cisternae, the appearance of myelin-like figures in the cytoplasm and an increase in the number of autophagosomal structures and multivesicular bodies characteristic of autophagy [39-42] (Fig. 2G).

Another class of enzyme inhibitor that has been extensively tested against $T$. cruzi is the cysteine protease inhibitors (CPI) [104-106]. They showed remarkable effects on GC structure in $T$. cruzi epimastigotes and intracellular amastigotes, which presented an increase in size and in the number of cisternae (from 5-7 to up to 16) in addition to the presence of dilated vesicles.

Epimastigotes and trypomastigotes treated with protein kinase (PK) and phosphatidylinositol-3 kinase inhibitors, such as genistein, staurosporine and wortmannin, also presented autophagosomal structures that were characterized by ER profiles surrounding several organelles [107].

Swelling of the ER-Golgi system is a common effect in $T$. cruzi trypomastigotes treated with reversed amidines [22, 23] and DAB [66]. Vinblastine treatment also caused Leishmania ER cisternae to protrude outward and to contact the plasma membrane [93].

Natural products like plant-derived drugs, essential oils and animal venoms have remarkable effects on protozoa. Proanthocyanidin (an ethanolic extract from the Kola acuminata plant) seems to drastically increase the $T$. brucei rough ER content and the Golgi apparatus, which present up to seven to eight cristae [108]. In addition to inducing ER profiles surrounding cytoplasmic membrane structures, $\beta$ lapachone derivatives also induced remarkable Golgi alterations, like disruption and enlargement of the trans-Golgi network cisternae $[55,56]$. Similarly, GG-OH treatment also caused effects on $T$. cruzi such as ER profiles surrounding organelles and myelin-like figures [72], suggesting an autophagic death pathway in response to both compounds. Dilation of the Golgi complex cisternae is also one of the effects of Brazilian green propolis on T. cruzi epimastigotes [109].

\subsection{Endocytic/ Exocytic Related Organelles}

The survival of trypanosomatids in distinct environments requires exogenous molecules that are internalized by fluidphase and receptor-mediated endocytosis [110-113]. The endocytic pathway in trypanosomatids presents a singular architecture, in which the intracellular itinerary and delivery of internalized molecules vary significantly according to the developmental form analyzed $[114,115]$. In trypomastigote forms of $T$. brucei, the endocytic/exocytic apparati are restricted to the posterior region of the cell between the flagellar pocket and the nucleus. However, in epimastigotes of $T$. cruzi and promastigotes of Leishmania, molecules that enter the cytostome or are internalized from the flagellar pocket pass through a network of tubules and vesicles extending from the anterior to the posterior end of the parasite [112, 116-118]. The nature and the morphological aspect of the compartments of the endocytic/exocytic pathway in trypanosomatids vary according the species analyzed. In African trypanosomes, the compartments are similar to those described in mammals, including the presence of lysosomes. Leishmania and T. cruzi, however, present different compartments that are potential drug targets.

Aromatic diamidines, such as pentamidine, caused remarkable changes in the flagellar pocket of amastigotes from L. tropica [12] and trypomastigotes of T. rhodesiense [119]. The flagellar pockets were frequently dilated and filled with double membrane-bound bodies that budded from the flagellar pocket membrane. The same phenomenon was also observed in promastigotes of L. amazonensis after incubation in the presence of azasterol and squalene synthase inhibitors, suggesting alterations in the secretory pathway $[41,44]$. 

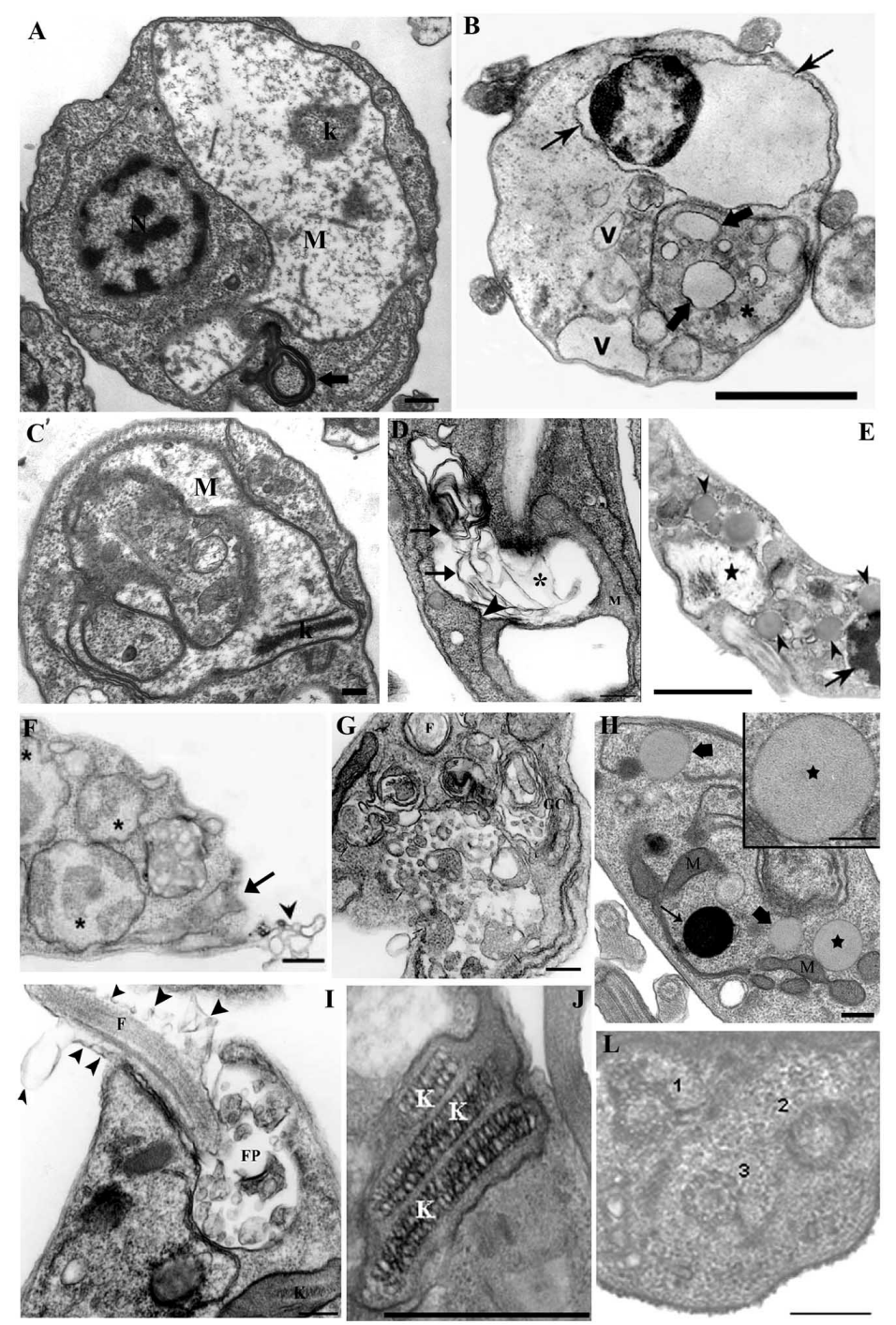

Fig. (2). Morphological alterations of parasites after different drug treatments. (A) An L. amazonensis promastigote treated with an SMT inhibitor for $96 \mathrm{~h}$ displaying a swollen mitochondrion and kinetoplast, altered nuclear chromatin distribution and presence of RE profiles (thick arrow). (B) Trypomastigote forms treated with naphthofuranquinone presenting mitochondrial swelling with intra-mitochondrial vesicle formation (thick arrows), increased cytoplasmic vacuoles (V), and strong nuclear envelope dilation (thin arrows). (C) L. amazonensis promastigotes showing intense mitochondrion swelling after $\Delta^{24(25)}$ sterol methenyl transferase inhibitor incubation. (D) L. amazonensis promastigotes forms presenting altered mitochondria with intense swelling and a less electron-dense matrix (arrows), alterations in the mitochondrial membranes such as the separation of the inner and outer membranes (arrowheads), and the presence of some concentric membranes and myelin figures in the matrix (arrows). (E) Naphthoimidazole (derived from $\beta$-lapachone) treatment leads to kDNA disorganization, swelling of the mitochondrion (asterisk), a decrease in the electron density of acidocalcisomes (arrowheads) and abnormal chromatin condensation (arrow). (F) Epimastigotes treated with edelfosine plus ketoconazole display alterations in the mitochondrion (arrow), plasma membrane (arrowheads), and appearance of multinucleated parasites (asterisks). (G) L. amazonensis promastigotes treated with $3 \mu \mathrm{M} \mathrm{BPQ-OH} \mathrm{for} 24 \mathrm{~h}$ display large vacuole-containing vesicles with a part of the cytoplasm, and some alterations in the Golgi complex (arrowheads). (H) L. amazonensis promastigotes treated with an SQS inhibitor showing the presence of many lipid droplets with distinct morphologies in the cytoplasm, a population of lipid bodies surrounded by a monolayer (thick arrows and star), and the presence of increased numbers of electrondense inclusions, confirming the alteration in the sterol content. (I) L. amazonensis promastigotes showing several alterations in the flagellar membrane (arrowheads) after BPQ-OH treatment. (J) Some epimastigotes treated with the alkaloid piperine display triple k-DNA without complete division of the parasite. (L) Suramin treatment results in differentiation of trypomastigotes, which present up to three basal bodies. $\mathrm{N}$, nucleus; K, kinetoplast; M, mitochondrion; F, flagellum. Bars: A, C: $6 \mu \mathrm{m}$; B, D, E: $2 \mu \mathrm{m}$; F: $0.25 \mu \mathrm{m}$; G: $0.15 \mu \mathrm{m}$; H: $0.5 \mu \mathrm{m}$; J, I: $1 \mu \mathrm{m}$; L: $0.3 \mu \mathrm{m}$. (A) Courtesy of J.C. Rodrigues; (B) Image reproduced with permission from Ref. [58] (C) (2009) Elsevier; (C) Courtesy of J.C. Rodrigues. (D) Image reproduced with permission from Ref. [40] (C) (2005) Elsevier; (E) Image reproduced with permission from Ref. [55] (C) (2005) Oxford University Press; (F) Image reproduced with permission from Ref. [51] () (2005) Oxford University Press; (G) Image reproduced with permission from Ref. [40] () (2005) Elsevier; (H) Image reproduced with permission from Ref. [41] ( ) (2007) American Society for Microbiology; (I) Image reproduced with permission from Ref. [40] ( (2005); (J) Image reproduced with permission from Ref. [84] (C) (2008) Springer-Verlag; (L) Image reproduced with permission from Ref. [92] (C) (2008) Elsevier. 
The lysophospholipid analogues (LPAs) edelfosine, miltefosine and ilmofosine, in addition to inducing the formation of vesicles and myelin-like figures in the flagellar pocket of L. amazonensis promastigotes [50], also induce morphological alterations in the reservosomes in epimastigotes of $T$. cruzi, which are characterized by swelling and the concentration of several reservosomes near the nucleus [51]. Reservosomes are also the main targets of cysteine protease antagonists. After incubation of epimastigotes in the presence of $\mathrm{Z}$-(SBz)Cys-Phe- $\mathrm{CHN}_{2}$, an irreversible cysteineprotease inhibitor, reservosomes became enlarged and more electron-dense [120].

Treatment with $\beta$-lapachone derivatives, anti-microtubule agents, risedronate or propolis induced various alterations in reservosome ultrastructure characterized by marked alterations in their morphology and in their electron density, due to inhibition of endocytic activity and/or to the increased degradation of the protein matrix. The presence of electronlucent rod-shaped inclusions was observed [56, 73, 74, 103, $109,121]$.

Active plant components also interfere with compartments of the endocytic pathway in trypanosomatids. The proanthocyanidin from Kola acuminata caused enlargement of the flagellar pocket and of the lysosome-like structures as well as the formation of multivesicular bodies in bloodstream T. brucei [108]. Flagellar pocket swelling was observed in L. chagasi promastigotes treated with Cymbopogon citratus essential oil [122].

\subsection{Acidocalcisomes}

The acidocalcisome is an acidic electron-dense organelle enclosed by a single membrane that is found in all members of the Trypanosomatidae family. The number and size of acidocalcisomes in a cell varies, and they can be observed in all developmental forms of $T$. cruzi, $T$. brucei and Leishmania. The electron-dense matrix contains sodium, magnesium, potassium, calcium, zinc, iron and phosphorous in the form of inorganic pyrophosphate and polyphosphate, as determined by electron microscopy microanalysis and energy-filtered transmission electron microscopy. In addition to storing the ions listed above, acidocalcisomes are also involved in $\mathrm{pH}$ homeostasis and osmoregulation. In some protozoan parasites (including trypanosomatids), the acidocalcisomes present enzymes that are not found or different from those found in mammals, such as the vacuolar proton translocating pyrophosphatase $\left(\mathrm{V}-\mathrm{H}^{+}\right.$-PPase) and a soluble inorganic pyrophosphatase (PPase) [123,124]. They are inhibited by various bisphosphonate pyrophosphate analogues, some of which are commercially available for the treatment of bone resorption diseases.

Aromatic diamidines, such as furamidine and the other fluorescent compounds suramine and chloroquine, were observed to accumulate in the acidocalcisomes of T. brucei [30, 31, 125]. Naphthoimidazole N1, a $\beta$-lapachone derivative, caused a decrease in the electron density of acidocalcisomes in T. cruzi trypomastigotes [55] (Fig. 2E). The most evident effect on the ultrastructure of acidocalcisomes was described in Leishmania amazonensis after treatment with the SBIs ketoconazole and terbinafine. The authors described a change in electron density of the cytoplasm, an increase in volume and in the number of the organelles, and the presence of acidocalcisome cores inside large vacuoles presenting characteristic autophagic-like structures. This last feature was also observed after incubation of Leishmania with the SBI 22, 26-azasterol [44]. An increase in acidocalcisome volume was also observed after incubation of $L$ chagasi promastigotes in the presence of essential oil from $C$. citratus, Lippia sidoides, and Ocimum gratissimum [122].

\subsection{Glycosomes}

Glycosomes are spherical or elongated structures with a homogeneous matrix surrounded by a single membrane. Most of the glycolytic pathway of trypanosomatids takes place in this organelle [126]. Besides glycolytic activity, which in trypanosomatids plays an essential role in their ATP supply, other metabolic pathways have been described to occur in glycosomes, such as isoprenoid and sterol biosynthesis. The enzymes in the glycosomes that participate in the different metabolic pathways are structurally and kinetically different from those observed in mammalian hosts, making the glycosomes a promising target for new drugs against parasitic trypanosomatid protozoa. Glycosomes in monoxenous trypanosomatids also contain catalase and are thus considered a special type of peroxisome.

Ultrastructural changes in glycosomes have been described only after incubation in the presence of the SB inhibitor terbinafine, which caused an increase in the number of glycosomes in epimastigotes of $T$. cruzi [37]. The authors also observed glycosomes arranged in stacks after $144 \mathrm{~h}$ of treatment.

\section{FINAL REMARKS}

Cell biology studies using electron microscopy have made important contributions to the identification of main targets for different drugs against trypanosomatids and to revealing their effects at the cellular level. New synthetic and natural compounds used in nanomolar concentrations and combinations of new and old drugs have been successfully used. In addition to the most commonly observed effects, which are mitochondrial swelling and cytoplasm vacuolization, some drugs cause a complex sequence of ultrastructural damage, indicating the progression of apoptosis-like and autophagic cell death in Leishmania and T. cruzi $[127,128]$.

\section{ACKNOWLEDGMENTS}

This work was supported by the Brazilian agencies Conselho Nacional de Desenvolvimento Científico e Tecnológico $(\mathrm{CNPq})$, Programa de Núcleos de Excelência (PRONEX), Fundação Carlos Chagas Filho de Amparo à Pesquisa do Estado do Rio de Janeiro (FAPERJ) and Coordenação de Aperfeiçoamento de Pessoal de Nível Superior (CAPES). The authors are grateful to Dr. Juliany Colla Fernandes Rodrigues and Dr. Wanderley de Souza for kindly providing some of the micrographs observed in Fig. (2). This review is in celebration of the 100th anniversary of the discovery of Chagas disease.

\section{REFERENCES}

[1] Trouiller P, Torreele E, Olliaro P, et al. Drugs for neglected diseases: a failure of the market and a public health failure? Trop Med Int Health 2001; 6: 945-51. 
[2] Reddy M, Gill SS, Kalkar SR, Wu W, Anderson PJ, Rochon PA. Oral drug therapy for multiple neglected tropical diseases: a systematic review. JAMA 2007; 298: 1911-24.

[3] De Azevedo Jr WF, Soares MBP. Selection of targets for drug development against protozoan parasites. Cur Drug Targets 2009; 10: 193-201.

[4] Docampo R, Moreno SNJ. Current chemotherapy of human African trypanosomiasis. Parasitol Res 2003; 90: S10-13.

[5] Anthony JP, Fyfe L, Smith H. Plant active components- a resource for antiparasitic agents? Trends Parasitol 2005; 21: 462-8.

[6] Ciscotto P, Machado de Avila RA, Coelho EAF, et al. Antigenic, microbicidal and antiparasitic properties of an ${ }_{\mathrm{L}}$-amino acid oxidase from Bothrops jararaca snake venom. Toxicon 2009; 53: 330-41.

[7] Soeiro MNC, Dantas AP, Daliry A, et al. Experimental chemotherapy for Chagas disease: 15 years of research contributions from in vivo and in vitro studies. Mem Inst Oswaldo Cruz 2009; 104: 301-10.

[8] De Souza W. Electron microcopy of trypanosomes - A historical review. Mem Inst Oswaldo Cruz 2008; 103: 313-25.

[9] De Souza W, Rodrigues JCF. Sterol Biosynthesis pathway as target for anti-trypanosomatid drugs. Interdiscip Perspect Infect Dis 2009; $1-9$.

[10] Vannier-Santos MA, De Castro SL. Electron microscopy in antiparasitic chemotherapy: a (close) view to a kill. Curr Drug Targets 2009; 10: 246-60.

[11] Williamson J, Macadam RF, Dixon H. Drug-induced lesions in trypanosome fine structure: a guide to modes of trypanocidal action. Biochem Pharmacol 1975; 24: 147-51.

[12] Hentzer B, Kobayasi T. The ultrastructural changes of Leishmania tropica after treatment with pentamidine. Ann Trop Med Parasitol 1977; 71: 157-66

[13] Croft SL, Brazil RP. Effect of pentamidine isethionate on the ultrastructure and morphology of Leishmania mexicana amazonensis in vitro. Ann Trop Med Parasitol 1982; 76: 37-43.

[14] Gadelha FR, Moreno SNJ, De Souza W, Crus FS, Docampo R. the mitochondrion of Trypanosoma cruzi is a target of crystal violet toxicity. Mol Biochem Parasitol 1989; 34: 117-26.

[15] Soeiro MNC, De Castro SL, De Souza EM, Batista DGJ, Silva CF, Boykin DW. Diamidines activity upon trypanosomes: the state of the art. Curr Mol Pharmacol 2008; 1: 151-61.

[16] Oliaro P, Guerin P, Gerstl S, Haaskjold A, Rottingen J, Sundar S. Treatment opitions for visceral leishmaniasis; a systematic review of clinical studies done in India, 1980-2004. Lancet Infect Dis 2005; 5: 763-74

[17] Werbovetz K. Diamidines as antitrypanosomal, antileishmanial and antimalarial agents. Curr Opin Investig Drugs 2006; 7: 147-57.

[18] De Souza EM, Lansiaux A, Bailly C, et al. Phenyl substitution of furamidine markedly potentiates its antiparasitic activity against Trypanosoma cruzi and Leishmania amazonensis. Biochem Pharmacol 2004; 68: 593-600.

[19] Mathis AM, Holman JL, Sturk LM, et al. Accumulation and intracellular distribution of antitrypanosomal diamidine compounds DB75 and Db820 in African trypanosomes. Antimicrob Agents Chemother 2006; 50: 2185-91.

[20] De Souza EM, Oliveira GM, Boykin DW, Kumar A, Hu Q, Soeiro MN. Trypanocidal activity of the phenyl-substituted analogue of furamidine DB569 against Trypanosoma cruzi infection in vivo. J Antimicrob Chemother 2006; 58: 610-4.

[21] De Souza EM, Menna-Barreto RFS, Araújo-Jorge TC, et al. Antiparasitic activity of aromatic diamidines is related to apoptosis-like death in Trypanosoma cruzi. Parasitology 2006; 133: 75-9.

[22] Silva CF, Batista MM, Mota RA, et al. Activity of "reversed" diamidines against Trypanosoma cruzi "in vitro". Biochem Pharmacol 2007; 73: 1939-346.

[23] Silva CF, Batista MM, De Souza EM, et al. Cellular effects of reversed amidines on Trypanosoma cruzi. Antimicrob Agents Chemother 2007; 51: 3803-9.

[24] Silva CF, Batista MM, Batista DG, et al. In vitro and in vivo studies of the trypanocidal activity of a diarylthiophene diamidine against Trypanosoma cruzi. Antimicrob Agents Chemother 2008; 52: 3307-14

[25] Pacheco MG, Da Silva CF, Da Souza EM, et al. Trypanosoma cruzi: activity of heterocyclic cationic molecules in vitro. Exp Parasitol 2009; 123: 73-80.
[26] Daliry A, Da Silva PB, Da Silva CF, et al. In vitro analyses of the effect of aromatic diamidines upon Trypanosoma cruzi. J Antimicrob Chemother 2009; 64: 747-50.

[27] Langreth SG, Berman JD, Riordan GP, Lee LS. Fine-structural alterations in Leishmania tropica within human macrophages exposed to antileishmanial drugs in vitro. J Protozool 1983; 30: 55561

[28] Fusai T, Boulard Y, Durand R, et al. Ultrastructural changes in parasites induced by nanoparticle-bound pentamidine in a Leishmania major/mouse model. Parasite 1997; 4: 133-9.

[29] Loiseau PM, Mbongo N, Bories C, Boulard Y, Craciunescu DG. In vivo antileishmanial action of Ir-(COD)-pentamidine tetraphenylborate on Leishmania donovani and Leishmania major mouse models. Parasite 2000; 7: 103-8.

[30] Mathis AM, Holman JL, Sturk LM, et al. Accumulation and intracellular distribution of antitrypanosomal diamidine compounds DB75 and Db820 in African trypanosomes. Antimicrob Agents Chemother 2006; 50: 2185-91.

[31] Mathis AM, Bridges AS, Ismail MA, et al. Diphenyl furans and aza analogs: effects of structural modification on in vitro activity, DNA binding, and accumulation and distribution in trypanosomes. Antimicrob Agents Chemother 2007; 51: 2801-10.

[32] Lanteri CA, Tidwell RR, Meshnick SR. The mitochondrion is a site of Trypanocidal action of the aromatic diamidine DB75 in bloodstream forms of Trypanosoma brucei. Antimicrob Agents Chemother 2008; 52: 875-82.

[33] Barrett-Bee K, Ryder N. Biochemical aspects of ergosterol biosynthesis inhibition. In: Sutcliffe J, Georgopapadakou NH, Ed. Emerging Targets in Antibacterial and Antifungal Chemotherapy New York, Chapmand and Hall 1992; pp. 410-36.

[34] Rodan GA. Mechanisms of action of bisphosphonates. Ann Rev Pharm Toxicol 1998; 38: 375-88.

[35] Charlton-Menys V, Durrington PN. Squalene synthase inhibitors: clinical pharmacology and cholesterol-lowering potential. Drugs 2007; 67: 11-6.

[36] Rodrigues CO, Catisti R, Uyemura SA, et al. The sterol composition of Trypanosoma cruzi changes after growth in different culture media and results in different sensitivity to digitoninpermeabilization. J Eukaryot Microbiol 2001; 48: 588-94.

Lazardi K ,Urbina JA, and De Souza W. Ultrastructural alterations induced by two ergosterol biosynthesis inhibitors, ketoconazole and terbinafine, on epimastigotes and amastigotes of Trypanosoma (Schizotrypanum) cruzi. Antimicrob Agents Chemother 1990; 34: 2097-105.

[38] Vannier-Santos MA, Urbina JA, Martiny A, Neves A, De Souza W. Alterations induced by the antifungal compounds ketoconazole and terbinafine in Leishmania. J Eukaryot Microbiol 1995; 42: 337 -

[39] Braga MV, Urbina JA, de Souza W. Effects of squalene synthase inhibitors on the growth and ultrastructure of Trypanosoma cruzi. Int J Antimicrob Agents 2004; 24: 72-8.

[40] Rodrigues JC, Urbina JA, de Souza W. Antiproliferative and ultrastructural effects of BPQ-OH, a specific inhibitor of squalene synthase, on Leishmania amazonensis. Exp Parasitol 2005; 111: 230-8.

[41] Rodrigues JCF, Concepcion JL, Rodrigues C, Caldera A, Urbina JA, de Souza W. In vitro Activities of ER-119884 and E5700, Two Potent Squalene Synthase Inhibitors, against Leishmania amazonensis: Antiproliferative, Biochemical, and Ultrastructural Effects. Antimicrob Agents Chemother 2008; 52(11): 4098-114.

[42] Granthon AC, Braga MV, Rodrigues JCF, et al. Alterations on the growth and ultrastructure of Leishmania chagasi induced by squalene synthase inhibitors. Vet Parasitol 2007; 146: 25-34.

[43] Vivas J, Urbina JA, De Souza W. Ultrastructural alterations in Trypanosoma (Schizotrypanum) cruzi induced by $\Delta^{24(25)}$ sterol methyl transferase inhibitors and their combinations with ketoconazole. Int J Antimicrob Agents 1996; 7: 235-40.

[44] Rodrigues JC, Attias M, Rodriguez C, Urbina JA, de Souza W. Ultrastructural and biochemical alterations induced by 22,26azasterol, a $\Delta^{24(25)}$-sterol methyltransferase inhibitor, on promastigote and amastigote forms of Leishmania amazonensis. Antimicrob Agents Chemother 2002; 46: 487-99.

[45] Magaraci F, Jimenez CJ, Rodrigues C, et al. Azasterols as inhibitors of sterol 24-methyltransferase in Leishmania species and Trypanosoma cruzi. J Med Chem 2003; 46: 4714-27.

[46] Braga MV, Magaraci F, Lorente SO, Gilbert I, de Souza W. Effects of inhibitors of $\Delta^{24(25)}$-sterol methyl transferase on the ultrastructure 
of epimastigotes of Trypanosoma cruzi. Microse Microanal 2005; 11: 506-15.

[47] Docampo R, Moreno SNJ, Turrens JF, Katzin AM, GonzaleaCappa SM, Stoppani AOM. Biochemical and ultrastructural alterations produced by miconazole and econazole in Trypanosoma cruzi. Mol Biochem Parasitol 1981; 3: 169-80.

[48] Jendrossek V, Handrick R. Membrane targeted anticancer drugs: potent inducers of apoptosis and putative radiosensitiesers. Curr Med Chem Anticancer Agents 2003; 3: 343-53.

[49] Urbina J. Mechanism of action of lysophospholipid analogues against trypanosomatid parasites. Trans R Soc Trop Med Hyg 2006; 1: S9-16.

[50] Santa-Rita RM, Henriques-Pons A, Barbosa HS, de Castro SL. Effect of the lysophospholipid analogues edelfosine, ilmofosine and miltefosine against Leishmania amazonensis. J Antimicrob Chemother 2004; 54: 704-10.

[51] Santa-Rita RM, Lira R, Barbosa HS, Urbina JA, de Castro SL. Anti-proliferative synergy of lysophospholipid analogues and ketoconazole against Trypanosoma cruzi (Kinetoplastida: Trypanosomatidae): cellular and ultrastructural analysis. J Antimicrob Chemother 2005; 55: 780-4

[52] Santa-Rita RM, Barbosa HS, de Castro SL. Ultrastructural analysis of edelfosine-treated trypomastigotes and amastigotes of Trypanosoma cruzi. Parasitol Res 2006; 100: 187-90.

[53] Pinto AV, Menna-Barreto RFS, De Castro SL. Naphtoquinones isolated from Tabebuia: a review about the synthesis of heterocyclic derivatives, screening against Trypanosoma cruzi and correlation structure-trypanocydal activity. In: Govil JN, Singh VK, Bhardwaj R, Ed. Recent Progress in Medicinal Plants, Phytomedicines 2007; vol. 16: pp. 112-27.

[54] Docampo R, Lopes JN, Cruz FS, De Souza W. Trypanosoma cruzi: Ultrastructural and metabolic alterations of epimastigotes by $\beta$ lapachone. Exp Parasitol 1977; 42: 142-9.

[55] Menna-Barreto RFS, Henriques-Pons A, Pinto AV, Morgado-Diaz JA, Soares MJ, De Castro SL. Effect of a $\beta$-lapachone-derived naphthoimidazole on Trypanosoma cruzi: identification of target organelles. J Antimicrob Chemother 2005; 56: 1034-41.

[56] Menna-Barreto RFS, Corrêa JR, Pinto AV, Soares MJ, De Castro SL. Mitochondrial disruption and DNA fragmentation in Trypanosoma cruzi induced by naphthoimidazoles synthesized from $\beta$ lapachone. Parasitol Res 2007; 101: 895-905.

[57] Menna-Barreto RF, Corrêa JR, Cascabulho CM, et al. Naphthoimidazoles promote different death phenotypes in Trypanosoma cruzi. Parasitol 2009; 136: 499-510.

[58] Menna-Barreto RFS, Gonçalves RLS, Costa EM, et al. The effects on Trypanosoma cruzi of novel synthetic naphthoquinones are mediated by mitochondrial dysfunction. Free Radic Biol Med 2009; 47: 644-53.

[59] Fairlamb AH, Cerami A. Metabolism and functions of trypanothione in the Kinetoplastida. Annu Rev Microbiol 1992; 46: 695-729.

[60] Ariyanayagam MR, Fairlamb AH. Diamine auxotrophy may be a universal feature of Trypanosoma cruzi epimastigotes. Mol Biochem Parasitol 1997; 84: 111-21.

[61] Carrillo C, Cejas S, Huber A, González NS, Algranati ID. Lack of arginine decarboxylase in Trypanosoma cruzi epimastigotes. J Eukaryot Microbiol 2003; 50: 312-6.

[62] Carrillo C, Canepa GE, Algranati ID, Pereira CA. Molecular and functional characterization of a spermidine transporter (TcPAT12) from Trypanosoma cruzi. Biochem Biophys Res Commun 2006; 344: 936-40.

[63] Steglich C, Schaeffer SW. The ornithine decarboxylase gene of Trypanosoma brucei: Evidence for horizontal gene transfer from a vertebrate source. Infect Genet Evol 2006; 6: 205-19.

[64] Bitonti AJ, McCann, PP, Bacchi CJ, Sjoerdsma A. Polyamine biosynthesis as a target for the chemotherapy of trypanosomatid infection. In: Coombs GH, North MJ, Ed. Biochemical Protozoology 1991; pp. 503-12.

[65] Gradoni L, Iorio MA, Gramiccia M, Orsini S. In vivo effect of eflornithine (DFMO) and some related compounds on Leishmania. Farmaco 1989; 44: 1157-66.

[66] Baumann RJ, Hanson WL, McCann PP, Sjoerdsma A, Bitonti AJ. Suppression of both antimony-susceptible and antimony-resistant Leishmania donovani by a bis(benzyl)polyamine analog. Antimicrob Agents Chemother 1990; 34: 722-7.
[67] Menezes D, Valentim C, Oliveira MF, Vannier-Santos MA. Putrescine analogue cytotoxicity against Trypanosoma cruzi. Parasitol Res 2006; 98: 99-105.

[68] Vannier-Santos MA, Menezes D, Oliveira MF, de Mello FG. The putrescine analogue 1,4-diamino-2-butanone affects polyamine synthesis, transport, ultrastructure and intracellular survival in Leishmania amazonensis. Microbiology 2008; 154: 3104-11.

[69] Rosa MS, Mendonça-Filho RR, Bizzo HR, et al. Antileishmanial activity of a linalool-rich essential oil from Croton cajucara. Antimicrob Agents Chemother 2003; 47: 1895-901.

[70] De Carvalho EA, Andrade PP, Silva NH, Pereira EC, Figueiredo RC. Effect of usnic acid from the lichen Cladonia substellata on Trypanosoma cruzi in vitro: an ultrastructural study. Micron 2005; 36:155-61.

[71] Kossuga MH, Nascimento AM, Reimão JQ, et al. Antiparasitic, antineuroinflammatory, and cytotoxic polyketides from the marine sponge Plakortis angulospiculatus collected in Brazil. J Nat Prod 2008; 71: 334-9.

[72] Menna-Barreto RFS, Laranja GAT, Silva MCC, et al. AntiTrypanosoma cruzi activity of Pterodon pubescens seed oil: geranylgeraniol as the major bioactive component. Parasitol Res 2008; 103: 111-7.

[73] Dantas AP, Salomão K, Barbosa HS, De Castro SL. The effect of Bulgarian propolis against Trypanosoma cruzi and during its interaction with host cells. Mem Inst Oswaldo Cruz 2006; 101: 207-11.

[74] Dantas AP, Barbosa HS, De Castro SL. Biological and ultrastructural effects of the anti-microtubule agent Taxol against Trypanosoma cruzi. J Submicrosc Cythol Pathol 2003; 35: 287-94.

[75] Traub-Cseko YM, Ramalho-Ortigão JM, Dantas AP, de Castro SL, Barbosa HS, Downing KH. Dinitroaniline herbicides against protozoan parasites: the case of Trypanosoma cruzi. Trends Parasitol 2001; 17: 136-41.

[76] Valdez RH, Tonin LT, Ueda-Nakamura T, et al. Biological activity of 1,2,3,4-tetrahydro-beta-carboline-3-carboxamides against Trypanosoma cruzi. Acta Trop 2009; 110: 7-14.

[77] Torres-Santos EC, Moreira DL, Kaplan MA, Meirelles MN, RossiBergmann B. Selective effect of 2',6'-dihydroxy-4'-methoxychalcone isolated from Piper aduncum on Leishmania amazonensis. Antimicrob Agents Chemother 1999; 43: 1234-41.

[78] Luize PS, Ueda-Nakamura T, Dias Filho BP, et al. Ultrastructural alterations induced by the neolignan dihydrobenzofuranic eupomatenoid-5 on epimastigote and amastigote forms of Trypanosoma cruzi. Parasitol Res 2006; 100: 31-7.

[79] De Souza W. Cell biology of Trypanosoma cruzi. Int Rev Cytol 1984; 86: 197-283

[80] Motta MC. Kinetoplast as a potential chemotherapeutic target of trypanosmatids. Curr Pharm Des 2008; 14: 847-54.

[81] Soeiro MNC, de Castro SL. Trypanosoma cruzi targets for new chemotherapeutic approaches. Expert Opin Ther Targets 2009; 13:105-21.

[82] Cavalcanti DP, Fragoso SP, Goldenberg S, de Souza W, Motta MC. The effect of topoisomerase II inhibitors on the kinetoplast ultrastructure. Parasitol Res 2004; 94: 439-48.

[83] Gonzales-Perdomo M, de Castro SL, Meirelles MN, Goldenberg S. Trypanosoma cruzi proliferation and differentiation are blocked by topoisomerase II inhibitors. Antimicrob Agents Chemother 1990; 34: $1707-14$.

[84] Freire-de-Lima L, Ribeiro TS, Rocha GM, et al. The toxic effects of piperine against Trypanosoma cruzi: ultrastructural alterations and reversible blockage of cytokinesis in epimastigote forms. Parasitol Res 2008; 102: 1059-67.

[85] Batista DGJ, Pacheco MGO, Kumar A, et al. Biological, ultrastructural effect and subcellular localization of aromatic diamidines in Trypanosoma cruzi. Parasitology 2009; 21: 1-9.

[86] Tempone AG, Pimenta DC, Lebrun I, et al. Antileishmanial and antitrypanosomal activity of bufadienolides isolated from the toad Rhinella jimi parotoid macrogland secretion. Toxicon 2008; 52: 13 21.

[87] Santoro GF, Cardoso MG, Guimarães LGL, Mendonça LZ, Soares MJ. Trypanosoma cruzi: Activity of essential oils from Achillea millefolim L., Syzygium aromaticum L. and Ocimum basilicum L. on epimastigotes and trypomastigotes. Exp Parasitol 2007; 116: 283-90.

[88] Adade CM, Figueiredo RCBQ, De Castro SL, Soares MJ. Effect of L-leucine methyl ester on growth and ultrastructure of Trypanosoma cruzi. Acta Trop 2007; 101: 69-79. 
[89] Kerschmann RL, Wolfson JS, McHugh GL, Dickersin GR, Hooper DC, Swartz MN. Novobiocin-induced ultrastructural changes and antagonism of DNA synthesis in Trypanosoma cruzi amastigotes growing in cell-free medium. J Protozool 1989; 36: 14-20.

[90] Savoia D, Allice T, Tovo PA. Antileishmanial activity of HIV protease inhibitors. Int J Antimicrob Agents 2005; 26: 92-4.

[91] Santos LO, Marinho FA, Altoé EF, et al. HIV Aspartyl peptidase Inhibitors Interfere with Cellular Proliferation, Ultrastructure and Macrophage Infection of Leishmania amazonensis. PLoS One 2009; 4: 1-1.

[92] Bisaggio DF, Adade CM, Souto-Padrón T. In vitro effects of suramin on Trypanosoma cruzi. Int J Antimicrob Agents 2008; 31: 282-6.

[93] Borges VM, Lopes UG, de Souza W, Vannier-Santos MA. Cell structure and cytokinesis alterations in multidrug-resistant Leishmania (Leishmania) amazonensis. Parasitol Res 2005; 95: 906.

[94] De Souza W. Components of the Cell surface of Trypanosmatids. Prog Protistol 1989; 3: 87-184.

[95] McGwire BS, Olson CL, Tack BF, Engman DM. Killing of African trypanosomes by antimicrobial peptides. J Infect Dis 2003; 188: 146-52.

[96] Madison MN, Kleshchenko YY, Nde PN, Simmons KJ, Lima MF, Villalta F.Human defensin alpha-1 causes Trypanosoma cruzi membrane pore formation and induces DNA fragmentation, which leads to trypanosome destruction. Infect Immun 2007; 75: 4780-91.

[97] Luque-Ortega JR, Saugar JM, Chiva C, Andreu D, Rivas L. Identification of new leishmanicidal peptide lead structures by automated real-time monitoring of changes in intracellular ATP. Biochem J 2003; 375: 221-30.

[98] Bisaggio DF, Peres-Sampaio CE, Meyer-Fernandes JR, SoutoPadrón T. Ecto-ATPase activity on the surface of Trypanosoma cruzi and its possible role in the parasite-host cell interaction. Parasitol Res 2003; 91(4): 273-82.

[99] Bisaggio DF, Campanati L, Pinto RC, Souto-Padrón T. Effect of suramin on trypomastigote forms of Trypanosoma cruzi: changes on cell motility and on the ultrastructure of the flagellum-cell body attachment region. Acta Trop 2006; 98: 162-75.

[100] Souto-Padrón T, Cunha e Silva NL, de Souza W. Acetylated alphatubulin in Trypanosoma cruzi: immunocytochemical localization. Mem Inst Oswaldo Cruz 1993; 88: 517-28.

[101] De Souza W, Miranda K, Cunha e Silva NL, Souto-Padrón T. A review on the ultrastructure of Trypanosoma cruzi. In: Teixeira A, Vinaud M, Castro AM, Ed. Emerging Chagas Disease 2009; pp. 40-62.

[102] Havens CG, Bryant N, Asher L, et al. Cellular effects of leishmanial tubulin inhibitors on Leishmania donovani. Mol Biochem Parasitol 2000; 110: 223-36.

[103] Bogitsh BJ, Middleton OL, Ribeiro-Rodrigues R. Effects of the antitubulin drug trifluralin on the proliferation and metacyclogenesis of Trypanosoma cruzi epimastigotes. Parasitol Res 1999; 85: 475-80.

[104] Engel JC, Doyle PS, Palmer J, Hsieh L, Baiton DF, McKerrow JH. Growth arrest of $T$. cruzi by cysteine protease inhibitors is accompanied by alterations in Golgi complex and ER ultrastructure. J Cell Sci 1998; 111: 597-606.

[105] Engel JC, Doyle PS, Palmer J, Hsieh L, McKerrow JH. Cysteine protease inhibitors cure an experimental Trypanosoma cruzi infection. J Exp Med 1998; 188: 725-34.

[106] Engel JC, García CT, Hsieh L, Doyle PS, McKerrow JH. Upregulation of the secretory pathway in cysteine protease inhibitor-resistant Trypanosoma cruzi. J Cell Sci 2000; 113: 1345-54.

[107] Braga VB, de Souza W. Effects on protein kinase and phosphatidylinositol-3 kinase inhibitors on growth and ultrastructure of Trypanosoma cruzi. FEMS Microbiol Lett 2006; 256: 209-16.
[108] Kubata BK, Nagamune K, Murakami N, et al. Kola acuminata proanthocyanidins: a class of anti-trypanosomal compounds effective against Trypanosoma brucei. Int J Parasitol 2005; 35: 91-103.

[109] Salomão K, de Souza EM, Henriques-Pons A, Barbosa HS, de Castro SL. Brazilian Green Propolis: Effects In vitro and In vivo on Trypanosoma cruzi. Evid Based Complement Alternat Med 2009; eCAM: 1-12 doi:10.1093/ecam/nep014.

[110] De Souza W, Sant'Anna C, Cunha-e-Silva N. Electron microscopy and cytochemistry analysis of the endocytic pathway of pathogenic protozoa. Prog Histochem Cythochem 2009; 44: 67-124.

[111] Coppens I, Opperdoes FR, Courtoy PJ, Baudhuin P. Receptormediated endocytosis in the bloodstream form of Trypanosoma brucei. J Protozool 1987; 34: 465-73.

[112] Webster P. Endocytosis by African trypanosomes.I. Threedimensional structure of the endocytic organelles in Trypanosoma brucei and T. congolense. Eur J Cell Biol 1989; 49: 295-302.

[113] Soares MJ, De Souza W. Endocytosis of gold-labeled proteins and LDL by Trypanosoma cruzi. Parasitol Res 1991; 77: 461-8.

[114] Clayton C, Hausler T, Blattner J. Protein trafficking in kinetoplastid protozoa. Microbiol Rev 1995; 59: 325-44.

[115] McConville MJ, Mullin KA, Ilgoutz SC, Teasdale RD. Secretory pathway of trypanosomatid parasites. Microbiol Mol Biol Rev 2002; 66: 122-54.

[116] Webster P, Fish WR. Endocytosis in African trypanosomes II. Occurrence in different life-cycle stages and intracellular sorting. Eur J Cell Biol 1989; 49: 3003-10.

[117] Porto-Carreiro I, Attias M, Miranda K, De Souza W, Cunha-e-Silva N. Trypanosoma cruzi epimastigotes endocytic pathway: cargo enters the cytostome and passes through an early endosomal network before storage in reservosomes. Eur J Cell Biol 2000; 79: 858-69.

[118] Weise F, Stierhof YD, Kuhn C, Weise M, Overath P. Distribution of GPI-anchored proteins in the protozoan parasites Leishmania based on an improved ultrastructural description using highpressure frozen cells. J Cell Sci 2000; 113: 4587-603.

[119] MacAdam RF, Williamson J. The effect of drugs on the finestructure of trypanosomes. Parasitology 1967; 57: 21-2.

[120] Yong V, Schmitz V, Vannier-Santos MA, et al. Altered expression of cruzipain and a cathepsin B-like target in a Trypanosoma cruzi cell line displaying resistance to synthetic inhibitors of cysteineproteinases. Mol Biochem Parasitol 2000; 109: 47-59.

[121] Garzoni LR, Caldera A, Meirelles MNL, et al. Selective in vitro effects of the farnesyl pyrophosphate synthase inhibitor risedronate on Trypanosoma cruzi. Int J Antimicrob Agents 2004; 23: 273-85.

[122] Oliveira VCS, Moura DMS, Lopes JAD, Andrade PP, da Silva NH, Figueiredo RCBQ. Effects of essential oils from Cymbopogon citratus (DC) Stapf., Lippia sidoides Cham., and Ocimum gratissimum L., on growth and ultrastructure of Leishmania chagasi promastigotes. Parasitol Res 2009; 104: 1053-9.

[123] Miranda K, Docampo R, Grillo O, de Souza W. Acidocalcisomes of trypanosmatids have species-specific elemental composition. Protist 2004; 155: 395-405.

[124] Moreno SN, Docampo R. The role of acidocalcisomes in parasitic protists. J Eukaryot Microbiol 2009; 56: 208-13.

[125] Coppens I, Baudhuin P, Opperdoes FR, Courtoy PJ. Role of acidic compartments in Trypanosoma brucei, with special reference to low-density lipoprotein processing. Mol Biochem Parasitol 1993; 58: 223-32.

[126] Opperdoes FR, Borst P. Localization of nine glycolytic enzymes in a microbody-like organelle in Trypanosoma brucei: the glycosome. FEBS Lett 1977; 15: 80: 360-4.

[127] Menna-Barreto RF, Salomão K, Dantas AP, et al. Different cell death pathways induced by drugs in Trypanosoma cruzi: an ultrastructural study. Micron 2009; 40: 157-68.

[128] Rodrigues JC, de Souza W. Ultrastructural alterations in organelles of parasitic protozoa induced by different classes of metabolic inhibitors. Curr Pharm Des 2008; 14: 925-38.

This is an open access article licensed under the terms of the Creative Commons Attribution Non-Commercial License (http://creativecommons.org/licenses/by-nc/3.0/) which permits unrestricted, non-commercial use, distribution and reproduction in any medium, provided the work is properly cited. 